\title{
Age-Related Association between Apolipoprotein E $\varepsilon 4$ and Cognitive Function in Japanese Patients with Alzheimer's Disease
}

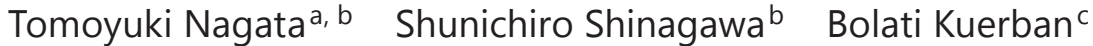 \\ Nobuto Shibatac Tohru Ohnumac Heii Araic Kazuhiko Nakayamab \\ Hisashi Yamada ${ }^{a}$ \\ a Division of Molecular Genetics, Institute of DNA Medicine, and ${ }^{\mathrm{b}}$ Department of Psychiatry, \\ Jikei University School of Medicine, and ${ }^{\mathrm{C}}$ Department of Psychiatry, Juntendo University \\ School of Medicine, Tokyo, Japan
}

Key Words

Alzheimer's disease · Memory disorders · Apolipoprotein E - Working memory ·

Polymorphism

\section{Abstract}

Aims: In the present study, we investigated whether apolipoprotein E (APOE) polymorphisms influenced the cognitive function of Japanese patients with Alzheimer's disease (AD) at certain ages. Methods: Among 200 outpatients with dementia and amnestic mild cognitive impairment, 133 Japanese patients with $A D$ were recruited and divided into two genotypic groups: $A P O E \& 4$ carriers and noncarriers. Then, we compared several neuropsychological test scores between the two genotypic groups for two different generations: 70 s (70-79 years) and $80 \mathrm{~s}$ (80-89 years). Results: The total Mini-Mental State Examination score $(p<0.05)$ and one of its subtest scores, the 3 -stage command score $(p<0.01)$, were significantly lower for the $\varepsilon 4$ carriers than for the noncarriers among patients in their 80s, but not among those in their 70s. The duration of illness differed significantly between the $\varepsilon 4$ carriers and the noncarriers among subjects in their 80 s but was not correlated with cognitive function. Conclusion: The present results suggest that $A P O E$ may significantly influence comparatively simple memory processing in certain generations of Japanese patients with $A D$.

Copyright $(2013$ S. Karger AG, Basel 
Nagata et al.: Age-Related Association between Apolipoprotein E $\varepsilon 4$ and Cognitive

Function in Japanese Patients with Alzheimer's Disease

\section{Introduction}

Apolipoprotein E (APOE), phosphatidylinositol-binding clathrin assembly protein, and clusterin have been reported as candidate genes for Alzheimer's disease (AD) in a recent genome-wide study [1]. Among these candidate genes, APOE polymorphisms have been reported as being associated with a robust genetic risk of AD since the 1990s, and $\varepsilon 4$ carriers are about three times more susceptible to $\mathrm{AD}$ than noncarriers $[1,2]$. The relation between the $A P O E$ gene and the risk of $\mathrm{AD}$ has been investigated in populations all over the world, and a significant association between $\varepsilon 4$ allele carriers and the manifestation of AD has been accepted. In Japan, a significant association between APOE $\varepsilon 4$ carriers and the manifestation of AD has been reported in a large-scale study [3].

The $A P O E$ gene has functional roles: it influences onset age, induces morphological changes in the hippocampus, and causes neural vulnerability via cerebrovascular mechanisms $[2,4-9]$. Regarding the influences on cognition, previous studies have reported that memory impairment or executive function is poorer in $\varepsilon 4$ carriers than in noncarriers among patients with $\mathrm{AD}[6,7,10]$. Moreover, from age-related viewpoints, the APOE gene tends to have a robust influence on the cognition of patients with $\mathrm{AD}$ who are in their 70 s or $80 \mathrm{~s}[2,7,11]$.

In Japan, while the $A P O E$ \&4 allele is associated with late-onset manifestation, a few reports have shown that it also influences cognitive function, neuroimaging, and neurobiological data $[3,8,9,12]$. A previous report has shown a significant difference in memory decline among three genotypic groups classified according to $\varepsilon 4$; however, the age of these three groups differed significantly [8]. Regarding clinical function in AD patients, cognitive impairment directly influences activities of daily living and might lead to subsequent behavioral and psychological problems (e.g. persecutory delusion and aberrant motor behavior) $[13,14]$. Therefore, the investigation of risk factors of cognitive decline might have an impact on the prevention of subsequent problems.

The aims of the present study were to examine whether APOE $\varepsilon 4$ influences cognitive function and to analyze its relation to the cognitive profiles of Japanese AD patients. Thus, we retrospectively compared two representative screening test scores, the Mini-Mental State Examination (MMSE) reflecting memory or attentional function and the Frontal Assessment Battery (FAB) reflecting executive function, among APOE $\varepsilon 4$ carriers (homozygous and heterozygous) and noncarriers in two different generations (70s: 70-79 years old and 80s: $80-89$ years old) that tend to be influenced by the $A P O E$ gene $[7,11,15,16]$.

\section{Methods}

\section{Participants}

Two hundred Japanese outpatients with dementia (AD: $n=133$; dementia with Lewy bodies: $\mathrm{n}=5$; frontotemporal lobar degeneration: $\mathrm{n}=8$; subcortical vascular dementia or mixed-type dementia: $n=10$, and idiopathic normal pressure hydrocephalus: $n=2$ ) and amnestic mild cognitive impairment (A-MCI: $n=42$ ) from among consecutive memory clinic outpatients visiting the Jikei University Hospitals (Tokyo or Kashiwa) participated in the present genomic study. One hundred and thirty-three consecutive Japanese patients with AD were recruited from among the above-mentioned patients. All AD patients were diagnosed as having probable AD based on the National Institute of Neurology and Communicative Disorder and Stroke/Alzheimer's Disease and Related Disorder Association (NINCDS/ADRDA) criteria [17]. Forty-two patients were diagnosed as having A-MCI according to the diagnostic criteria for MCI [18]. APOE genotypes for all patients with AD were identified at the Department of Psychiatry, Juntendo University School of Medicine, based on a method used in pre- 
Nagata et al.: Age-Related Association between Apolipoprotein E $\varepsilon 4$ and Cognitive

Function in Japanese Patients with Alzheimer's Disease

vious reports $[19,20]$. Next, we divided the 133 subjects into two groups according to whether they were $\varepsilon 4$ carriers or noncarriers. Among the subjects' detailed demographic variables, behavioral and psychological symptoms were assessed based on information obtained from a structured interview with each patient's caregiver. The interviews were conducted by the same geriatric psychiatrists using the Behavioral Pathology in Alzheimer's disease (BehaveAD) scale [21]. To investigate neuropsychological characteristics, two representative screening tests, the MMSE (ranging from 0 to 30 ) reflecting memory or attentional function and the FAB (ranging from 0 to 18 ) reflecting executive function, were administered by a clinical psychologist $[15,16]$. To determine the severity of each patient's dementia, the geriatric psychiatrists used the Clinical Dementia Rating-Sum of Boxes (CDR-SB: ranging from 0 to 18) based on information provided by each patient's caregiver [22]. The two geriatric psychiatrists and the clinical psychologist were experienced at performing neuropsychological and behavioral examinations, and the interrater validity of the scales was sustained by periodic discussions and exchanges of views. This study was approved by the Ethics Committees of the Jikei University School of Medicine (Tokyo and Kashiwa), and written informed consent was obtained from both the patients and their caregivers.

Comparison of FAB and MMSE Test Scores between the Two Groups according to Two Generations: 70 s and 80 s

The APOE gene tends to influence the cognition of patients with $\mathrm{AD}$ who are in their $70 \mathrm{~s}$ or 80 s $[2,7,11]$. Thus, we compared the MMSE and FAB scores between $\varepsilon 4$ carriers and noncarriers according to two different generations: 70s and 80s.

\section{Statistical Analysis}

SPSS 19.0J for Windows (SPSS Japan Inc.) was used for all statistical analyses. To control for type I errors, we used one-way ANOVA with a post hoc Tukey test for assessment of age of the participants in the present study, education years, duration of illness (in months; from age at onset until entry in the present study) as well as MMSE, Behave-AD, CDR-SB, and FAB scores and compared them between $\varepsilon 4$ carriers and noncarriers. Seven MMSE subtest scores (with possible scores with a range of 0-5 for 'time orientation', 0-5 for 'place orientation', 0-3 for 'registration', 0-5 for 'attention and calculation', 0-3 for 'recall', 0-2 for 'naming', and 0-3 for ' 3 -stage command') and six FAB subtest scores (with possible scores ranging from 0-3 for 'similarities', 'lexical fluency', 'motor series', 'conflicting instructions', 'go/no go', and 'prehension behavior') were assessed using the Mann-Whitney test. The sex ratio (female/ male) and four other MMSE subtest scores (with possible scores with a range of $0-1$ for 'repetition', 'reading', 'writing', and 'copying') were assessed using the $\chi^{2}$ test. A p value $<0.05$ was considered statistically significant.

\section{Results}

\section{Patient Characteristics}

The APOE genotypes of $133 \mathrm{AD}$ patients were examined: 66 subjects were found to be $\varepsilon 4$ carriers $(\varepsilon 2 / \varepsilon 4: \mathrm{n}=3, \varepsilon 3 / \varepsilon 4: \mathrm{n}=48$, and $\varepsilon 4 / \varepsilon 4: \mathrm{n}=15)$ and 67 subjects to be noncarriers $(\varepsilon 2 /$ $\varepsilon 3: \mathrm{n}=5$ and $\varepsilon 3 / \varepsilon 3: \mathrm{n}=62$ ). Among the demographic variables of all patients, only age at consultation was significantly lower among the $\varepsilon 4$ carriers than among the noncarriers $(\mathrm{F}=$ 15.324; d.f. $=1 ; \mathrm{p}<0.001$ ) (table 1). No significant differences in any other demographic variables were observed between the two genotypic groups in all AD patients (table 1). Regarding the age distribution of the patients in the present study, most of the subjects (88.7\%) were in their 70s or 80s (50s: $\mathrm{n}=2,60 \mathrm{~s}: \mathrm{n}=12,70 \mathrm{~s}: \mathrm{n}=56,80 \mathrm{~s}: \mathrm{n}=62$, and 90s: $\mathrm{n}=1$ ). 
Nagata et al.: Age-Related Association between Apolipoprotein E $\varepsilon 4$ and Cognitive Function in Japanese Patients with Alzheimer's Disease

Table 1. Comparison of subject characteristics (mean \pm SD) between APOE $\varepsilon 4$ carriers and noncarriers in patients with $\mathrm{AD}(\mathrm{n}=133)$

\begin{tabular}{lllrc}
\hline & $\begin{array}{l}\text { Noncarriers } \\
(\mathrm{n}=67)\end{array}$ & $\begin{array}{l}\varepsilon 4 \text { carriers } \\
(\mathrm{n}=66)^{\mathrm{b}}\end{array}$ & $\chi^{2}$ or F score & $\mathrm{p}$ value \\
\hline Sex (male/female) & $21 / 46$ & $16 / 50$ & $0.835^{\mathrm{c}}$ & 0.361 \\
Age, years & $80.73 \pm 5.68$ & $76.39 \pm 7.07$ & 15.324 & $<0.001^{*}$ \\
Duration of illness, months & $29.76 \pm 18.99$ & $35.80 \pm 25.07$ & 2.459 & 0.119 \\
Education, years & $11.49 \pm 2.52$ & $11.92 \pm 3.06$ & 0.734 & 0.393 \\
MMSE score & $19.39 \pm 4.86$ & $18.88 \pm 4.63$ & 0.389 & 0.534 \\
FAB score & $11.02 \pm 3.5$ & $10.68 \pm 3.76$ & 0.243 & 0.623 \\
Behave-AD score & $7.43 \pm 5.01$ & $8.05 \pm 5.95$ & 0.413 & 0.521 \\
CDR-SB $^{\text {a }}$ & $6.88 \pm 3.11$ & $6.78 \pm 2.96$ & 0.036 & 0.849 \\
\hline
\end{tabular}

Sex was analyzed using the $\chi^{2}$ test. Other variables were analyzed using one-way ANOVA with post hoc tests (Tukey). ${ }^{\mathrm{a}}$ Ranging from 0 to $18 .{ }^{\mathrm{b}}$ Heterozygotes: 51 , homozygotes: $15 .{ }^{\mathrm{c}}$ The $\chi^{2}$ score is given. ${ }^{*} \mathrm{p}<0.001$.

Table 2. Comparison of subject characteristics (mean \pm SD) between $A P O E \varepsilon 4$ carriers and noncarriers in patients with AD who were $70-79$ years old $(n=56)$

\begin{tabular}{lllll}
\hline & $\begin{array}{l}\text { Noncarriers } \\
(\mathrm{n}=24)\end{array}$ & $\begin{array}{l}\varepsilon 4 \text { carriers } \\
(\mathrm{n}=32)^{\mathrm{b}}\end{array}$ & $\chi^{2}$ or F score & $\mathrm{p}$ value \\
\hline Sex (male/female) & $11 / 13$ & $5 / 27$ & $6.132^{\mathrm{c}}$ & $0.013^{*}$ \\
Age, years & $76.29 \pm 2.94$ & $76.25 \pm 1.98$ & 0.004 & 0.95 \\
Duration of illness, months & $33.50 \pm 19.39$ & $29.03 \pm 25.11$ & 0.525 & 0.472 \\
Education, years & $12.08 \pm 2.04$ & $11.97 \pm 3.18$ & 0.024 & 0.878 \\
MMSE score & $18.13 \pm 6.11$ & $19.72 \pm 4.43$ & 1.250 & 0.269 \\
FAB score & $11.68 \pm 3.15$ & $11.43 \pm 3.97$ & 0.055 & 0.815 \\
Behave-AD score & $6.92 \pm 5.09$ & $7.53 \pm 4.70$ & 0.218 & 0.642 \\
CDR-SB & $6.81 \pm 3.18$ & $5.75 \pm 2.71$ & 1.822 & 0.183 \\
\hline
\end{tabular}

Sex was analyzed using the $\chi^{2}$ test. Other variables were analyzed using one-way ANOVA with post hoc

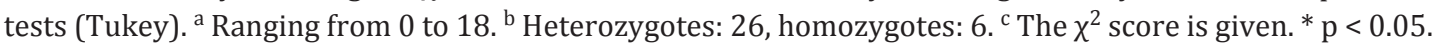

Comparison of Demographic Variables between $\varepsilon 4$ Carriers and Noncarriers in Their $70 \mathrm{~s}$

We found a significant difference in the sex ratio $\left(\chi^{2}=6.132\right.$; d.f. $\left.=1 ; \mathrm{p}=0.013\right)$ between $\varepsilon 4$ carriers (male/female: 5/27) and noncarriers (male/female: 11/13), but no significant differences in any other demographic variables (table 2). To investigate whether the APOE genotypes ( $\varepsilon 4$ carriers or noncarriers) or the sex ratio (female/male) affected the MMSE or FAB scores, we performed a generalized linear model analysis (ANOVA). As a result, significant interactions between these two factors were not observed for the MMSE and FAB scores in a generalized linear model analysis (former: $F=1.719$; d.f. $=1 ; p=0.196$, latter: $F=0.001$; d.f. $=1 ; p=0.971$ ).

Comparison of Demographic Variables between $\varepsilon 4$ Carriers and Noncarriers in Their $80 \mathrm{~s}$

The MMSE score was significantly lower $(F=5.757$; d.f. $=1 ; p=0.02)$ in the $\varepsilon 4$ carriers than in the noncarriers, and the duration of illness (months) was significantly longer ( $\mathrm{F}=$ 4.975 ; d.f. $=1 ; p=0.029$ ) in the $\varepsilon 4$ carriers than in the noncarriers (table 3 ). 
Nagata et al.: Age-Related Association between Apolipoprotein E ع4 and Cognitive

Function in Japanese Patients with Alzheimer's Disease

Table 3. Comparison of subject characteristics (mean \pm SD) between APOE \&4 carriers and noncarriers in patients with AD who were 80-89 years old $(n=62)$

\begin{tabular}{lcccc}
\hline & $\begin{array}{l}\text { Noncarriers } \\
(\mathrm{n}=41)\end{array}$ & $\begin{array}{l}\varepsilon 4 \text { carriers } \\
(\mathrm{n}=21)^{\mathrm{b}}\end{array}$ & $\chi^{2}$ or F score & $\mathrm{p}$ value \\
\hline Sex (male/female) & $9 / 32$ & $3 / 18$ & $0.523^{\mathrm{c}}$ & 0.473 \\
Age, years & $84.22 \pm 2.60$ & $82.81 \pm 2.89$ & 3.78 & 0.057 \\
Duration of illness, months & $28.44 \pm 18.78$ & $41.52 \pm 26.98$ & 4.975 & $0.029^{*}$ \\
Education, years & $11.02 \pm 2.68$ & $11.38 \pm 3.15$ & 0.218 & 0.642 \\
MMSE score & $19.98 \pm 4.02$ & $17.29 \pm 4.47$ & 5.757 & $0.02^{*}$ \\
FAB score & $10.58 \pm 3.69$ & $9.35 \pm 3.66$ & 1.358 & 0.249 \\
Behave-AD score & $7.88 \pm 5.07$ & $10.29 \pm 7.65$ & 2.199 & 0.143 \\
CDR-SB & $7.05 \pm 3.13$ & $8.52 \pm 3.01$ & 3.163 & 0.08 \\
\hline
\end{tabular}

Sex was analyzed using the $\chi^{2}$ test. Other variables were analyzed using one-way ANOVA with post hoc tests (Tukey). ${ }^{a}$ Ranging from 0 to $18 .{ }^{b}$ Heterozygotes: 18 , homozygotes: $3 .{ }^{c}$ The $\chi^{2}$ score is given. ${ }^{*} \mathrm{p}<0.05$.

MMSE Subtest Scores between 44 Carriers and Noncarriers in Their $80 \mathrm{~s}$

Among the MMSE subtest scores, the 3-stage command score of the $\varepsilon 4$ carriers was significantly lower than that of the noncarriers $(\mathrm{Z}=-3.007$; d.f. $=1 ; \mathrm{p}=0.003)$ (table 4). To investigate the $A P O E$ genotypes ( $\varepsilon 4$ carriers or noncarriers) and the duration of illness (months) as covariates affecting the MMSE total and 3-stage command scores, we performed a generalized linear model analysis (ANCOVA). As a result, a significant interaction between these two factors was not observed for the MMSE total and 3-stage command scores (former: $\mathrm{F}=$ 0.016 ; d.f. $=1 ; \mathrm{p}=0.900$, latter: $\mathrm{F}=0.216$; d.f. $=1 ; \mathrm{p}=0.644$ ).

FAB Total and Subtest Scores between $\varepsilon 4$ Carriers and Noncarriers in All AD Patients and

Patients in Their $70 \mathrm{~s}$ or $80 \mathrm{~s}$

No significant difference in the FAB total score was observed between the two genotypic groups among all AD patients or among the patients in their 70s or 80s (tables 1-3). Moreover, the six subtest scores were not significantly influenced by these genotypic groups among patients in their 70s or 80s (data not shown).

\section{Discussion}

As the results of the present study show, $A P O E \varepsilon 4$ significantly influenced the age at consultation in all AD patients (table 1). Furthermore, while APOE $\varepsilon 4$ influenced the MMSE total and its subtest score, the 3-stage command score, among subjects in their 80 s without any significant interaction with the duration of illness, such results were not observed in subjects in their 70s (tables 2-4). A previous study has reported that the onset age of AD in $A P O E \& 4$ carriers was younger than that in noncarriers, which might have influenced the significant differences in the age at consultation in all AD patients and the illness duration of the patients in their 80 s between the two genetic groups in the present study [2].

Some previous studies have shown that $A P O E \& 4$ has a significant effect on memory retention, rather than on executive function, in other ethnicities or countries, and our results support these reports [6, 7, 10]. From a cross-sectional viewpoint, Caselli et al. [7] showed that age-related differences in memory decline among $\varepsilon 4$ carriers and noncarriers increased with age. This could explain the present result, which indicates that a significant association 
Nagata et al.: Age-Related Association between Apolipoprotein E $\varepsilon 4$ and Cognitive Function in Japanese Patients with Alzheimer's Disease

Table 4. Comparison of MMSE subtest scores (mean \pm SD) between APOE $\varepsilon 4$ carriers and noncarriers in patients with AD who were $80-89$ years old $(n=62)$

\begin{tabular}{|c|c|c|c|c|}
\hline MMSE subtests (ranges) & $\begin{array}{l}\text { Noncarrier } \\
(\mathrm{n}=41)\end{array}$ & $\begin{array}{l}\varepsilon 4 \text { carrier } \\
(\mathrm{n}=21)^{\mathrm{a}}\end{array}$ & $\begin{array}{l}\chi^{2} \text { score or } \\
M-W Z \text { score }\end{array}$ & $\mathrm{p}$ value \\
\hline Orientation to time $(0-5)$ & $2.34 \pm 1.67$ & $1.71 \pm 1.42$ & -1.391 & 0.164 \\
\hline Orientation to place $(0-5)$ & $2.99 \pm 1.16$ & $2.62 \pm 1.24$ & -1.305 & 0.192 \\
\hline Registration $(0-3)$ & $2.90 \pm 0.30$ & $2.57 \pm 0.87$ & -1.616 & 0.106 \\
\hline Attention and calculation $(0-5)$ & $2.49 \pm 1.81$ & $2.05 \pm 1.77$ & -0.939 & 0.348 \\
\hline Recall $(0-3)$ & $1.15 \pm 1.15$ & $0.71 \pm 0.96$ & -1.412 & 0.158 \\
\hline Naming $(0-2)$ & $1.93 \pm 0.26$ & $1.86 \pm 0.36$ & -0.871 & 0.384 \\
\hline Repetition $(0-1)$ & $0.88 \pm 0.33$ & $0.76 \pm 0.44$ & $1.385^{\mathrm{b}}$ & 0.239 \\
\hline 3 -stage command $(0-3)$ & $2.95 \pm 0.22$ & $2.57 \pm 0.75$ & -3.007 & $0.003^{*}$ \\
\hline Reading $(0-1)$ & $0.93 \pm 0.26$ & $0.95 \pm 0.22$ & $0.15^{\mathrm{b}}$ & 0.698 \\
\hline Writing $(0-1)$ & $0.66 \pm 0.48$ & $0.81 \pm 0.40$ & $1.537^{\mathrm{b}}$ & 0.215 \\
\hline Copying $(0-1)$ & $0.71 \pm 0.46$ & $0.67 \pm 0.48$ & $0.108^{\mathrm{b}}$ & 0.742 \\
\hline
\end{tabular}

$\mathrm{M}-\mathrm{W}=$ Mann-Whitney test. ${ }^{\mathrm{a}}$ Heterozygotes: 18 , homozygotes: $3{ }^{\mathrm{b}}{ }^{\mathrm{T}}$ The $\chi^{2}$ score is given. ${ }^{*} \mathrm{p}<0.01$.

between $A P O E \varepsilon 4$ and cognitive function was found only in patients in their $80 \mathrm{~s}$, but not in those in their 70s. Wolk et al. [23] found that the APOE gene had double dissociable roles in memory and executive function through cortical morphometric evaluations performed in $\varepsilon 4$ carriers and noncarriers with AD. Luczywek et al. [6] reported that APOE $\varepsilon 4$ influences memory retention, rather than working memory, in patients with early-stage AD. However, we did not obtain similar results indicating a significant association between the $A P O E$ and FAB scores reflecting executive function.

Due to the effects of $A P O E \varepsilon 4$ on particular cognitive profiles, $\varepsilon 4$ carriers with AD have been reported to have greater hippocampal cortical atrophy, possibly leading to memory impairments $[4,9,23]$. In a previous study evaluating the characteristics of the MMSE subtest using a factor analysis, the registration and 3-stage command tests were identified as involving immediate or simple memory processing, whereas recall was identified as involving complex memory processing $[24,25]$. In the present study, a significant correlation was observed between the registration and the 3-stage command scores (Spearman correlation: $\rho=0.373$, $\mathrm{p}=0.003$ ), but not between the recall and the 3-stage command scores (Spearman correlation: $\rho=0.105, \mathrm{p}=0.418$ ) among patients in their 80s. Thus, APOE $\varepsilon 4$ might influence these comparatively simple memory processing tasks in Japanese patients with AD who are in their 80s.

The present study has some limitations. First, since the sample size was comparatively small, we could not compare cognitive function among the three genotypic groups (homozygous for $\varepsilon 4$, heterozygous for $\varepsilon 4$, and noncarriers) or in younger subjects in their $50 \mathrm{~s}$ or $60 \mathrm{~s}$. Therefore, some type I or type II errors might have occurred. For example, among subjects in their 80 s, the mean score for 'recall' of the $\varepsilon 4$ carriers was lower than that of the noncarriers, but the difference was not statistically significant $(p=0.158)$ (table 4). Furthermore, the statistical value $(\mathrm{p}=0.02)$ in the MMSE total score comparison was comparatively small (table 3). However, the effect sizes or statistical values were almost the same as those in previous reports $[7,8,10]$. The statistical significance of the 3-stage command score $(\mathrm{p}=$ $0.003)$ might be reasonable if a $p$ value of $<0.05 / 11(\fallingdotseq 0.0045)$ is regarded as a significant difference according to the Bonferroni correction, since the MMSE scale has 11 subtest scores (table 4). Second, we did not observe a significant association between $\varepsilon 4$ carriers and the 
Nagata et al.: Age-Related Association between Apolipoprotein E $\varepsilon 4$ and Cognitive

Function in Japanese Patients with Alzheimer's Disease

FAB scores reflecting executive function (tables 1-3), as described in previous reports [10, 23]. We used representative screening tests that could be completed at bedside without requiring any tools or instruments, and we believe that the simplicity of these tests makes them valuable tools. However, the ranges of the subtest scores were comparatively small; thus, other batteries for evaluating executive function might provide useful information. Third, a significant difference in the sex ratio of the subjects in their 70s was observed in the present study, with a higher frequency of female $\varepsilon 4$ carriers (table 2). However, Yasuno et al. [12] reported that the proportion of female elderly subjects with $\varepsilon 4$ was comparatively high in Japan. Moreover, a significant interaction between the sex ratio and APOE $\varepsilon 4$ was not shown for cognitive function in a generalized linear model analysis using ANOVA. Finally, among the subjects in their 80s, a significant difference in the duration of illness was shown, which might reflect differences in the age at consultation for $\mathrm{AD}$ among the two genotypic groups (table 3 ). However, a significant interaction of illness duration (in months) as a covariance was not shown for cognitive function in a generalized linear model analysis using ANCOVA.

In conclusion, despite some limitations, we found for the first time a significant effect of $A P O E \& 4$ on the MMSE score reflecting memory or attentional function (particularly for a simple memory processing task, the 3-stage command), rather than executive function, among Japanese AD patients in their 80s, which was a comparatively older generation. Our results support the findings of previous studies in other countries in addition to furthering the elucidation of the functional roles of the $A P O E$ gene $[6,7,10]$. Furthermore, defining the detailed associations between $A P O E$ gene diversity and cognitive behavior in patients with $\mathrm{AD}$ using an intermediate phenotype in studies involving neuroimaging or physiological methods in a normal elderly population will be an important task in the future.

\section{Acknowledgement}

We are grateful for the technical assistance of Ms. K. Yamamoto of the Juntendo University School of Medicine.

\section{References}

1 Harold D, Abraham R, Hollingworth P, Sims R, Gerrish A, Hamshere ML, Pahwa JS, Moskvina V, et al: Genomewide association study identifies variants at CLU and PICALM associated with Alzheimer's disease. Nat Genet 2009;41:1088-1093.

- 2 Corder EH, Saunders AM, Strittmatter WJ, Schmechel DE, Gaskell PC, Small GW, Roses AD, Haines JL, PericakVance MA: Gene dose of apolipoprotein E type 4 allele and the risk of Alzheimer's disease in late onset families. Science 1993;261:921-923.

- 3 Ohara T, Ninomiya T, Hirakawa Y, Ashikawa K, Monji A, Kiyohara Y, Kanba S, Kubo M: Association study of susceptibility genes for late-onset Alzheimer's disease in the Japanese population. Psychiatr Genet 2012;22: 290-293.

- 4 Lehtovirta M, Soininen H, Laakso MP, Partanen K, Helisalmi S, Mannermaa A, Ryynänen M, Kuikka J, Hartikainen P, Riekkinen PJ Sr: SPECT and MRI analysis in Alzheimer's disease: relation to apolipoprotein E epsilon 4 allele. J Neurol Neurosurg Psychiatry 1996;60:644-649.

5 Bell RD, Winkler EA, Singh I, Sagare AP, Deane R, Wu Z, Holtzman DM, Betsholtz C, Armulik A, Sallstrom J, Berk BC, Zlokovic BV: Apolipoprotein E controls cerebrovascular integrity via cyclophilin A. Nature 2012;485:512516.

6 Luczywek E, Nowicka A, Pfeffer A, Czyzewski K, Styczyńska M, Lałowski M, Barcikowska M: Cognitive deficits and polymorphism of apolipoprotein E in Alzheimer's disease. Dement Geriatr Cogn Disord 2002;13:171-177.

7 Caselli RJ, Dueck AC, Osborne D, Sabbagh MN, Connor DJ, Ahern GL, Baxter LC, Rapcsak SZ, Shi J, Woodruff BK, Locke DE, Snyder CH, Alexander GE, Rademakers R, Reiman EM: Longitudinal modeling of age-related memory decline and the APOE epsilon4 effect. N Engl J Med 2009;361:255-263.

8 Hirono N, Hashimoto M, Yasuda M, Kazui H, Mori E: Accelerated memory decline in Alzheimer's disease with apolipoprotein epsilon4 allele. J Neuropsychiatry Clin Neurosci 2003;15:354-358. 
9 Mori E, Lee K, Yasuda M, Hashimoto M, Kazui H, Hirono N, Matsui M: Accelerated hippocampal atrophy in Alzheimer's disease with apolipoprotein E epsilon4 allele. Ann Neurol 2002;51:209-214.

10 Caselli RJ, Dueck AC, Locke DE, Hoffman-Snyder CR, Woodruff BK, Rapcsak SZ, Reiman EM: Longitudinal modeling of frontal cognition in APOE $\varepsilon 4$ homozygotes, heterozygotes, and noncarriers. Neurology 2011;76: 1383-1388.

-11 Schiepers OJ, Harris SE, Gow AJ, Pattie A, Brett CE, Starr JM, Deary IJ: APOE E4 status predicts age-related cognitive decline in the ninth decade: longitudinal follow-up of the Lothian Birth Cohort 1921. Mol Psychiatry 2012;17:315-324.

-12 Yasuno F, Tanimukai S, Sasaki M, Hidaka S, Ikejima C, Yamashita F, Kodama C, Mizukami K, Michikawa M, Asada T: Association between cognitive function and plasma lipids of the elderly after controlling for apolipoprotein E genotype. Am J Geriatr Psychiatry 2012;20:574-583.

13 Martyr A, Clare L: Executive function and activities of daily living in Alzheimer's disease: a correlational metaanalysis. Dement Geriatr Cogn Disord 2012;33:189-203.

14 Nagata T, Shinagawa S, Ochiai Y, Kada H, Kasahara H, Nukariya K, Nakayama K: Relationship of frontal lobe dysfunction and aberrant motor behaviors in patients with Alzheimer's disease. Int Psychogeriatr 2010;22: 463-469.

15 Dubois B, Slachevsky A, Litvan I, Pillon B: The FAB: a Frontal Assessment Battery at bedside. Neurology 2000; 55:1621-1626.

-16 Folstein MF, Folstein SE, McHugh PR: 'Mini-mental state'. A practical method for grading the cognitive state of patients for the clinician. J Psychiatr Res 1975;12:189-198.

17 McKhann G, Drachman D, Folstein M, Katzman R, Price D, Stadlan EM: Clinical diagnosis of Alzheimer's disease: report of the NINCDS-ADRDA Work Group under the auspices of Department of Health and Human Services Task Force on Alzheimer's Disease. Neurology 1984;34:939-944.

-18 Petersen RC, Doody R, Kurz A: Current concepts in mild cognitive impairment. Arch Neurol 2001;58:19851992.

19 Wenham PR, Newton CR, Price WH: Analysis of apolipoprotein E genotypes by the Amplification Refractory Mutation System. Clin Chem 1991;37:241-244.

20 Shibata N, Ohnuma T, Baba H, Higashi S, Nishioka K, Arai H: Genetic association between SoRL1 polymorphisms and Alzheimer's disease in a Japanese population. Dement Geriatr Cogn Disord 2008;26:161-164.

21 Reisberg B, Borenstein J, Salob SP, Ferris SH, Franssen E, Georgotas A: Behavioral symptoms in Alzheimer's disease: phenomenology and treatment. J Clin Psychiatry 1987;48(suppl):9-15.

-22 Hughes CP, Berg L, Danziger WL, Coben LA, Martin RL: A new clinical scale for the staging of dementia. Br J Psychiatry 1982;140:566-572.

23 Wolk DA, Dickerson BC; Alzheimer's Disease Neuroimaging Initiative: Apolipoprotein E (APOE) genotype has dissociable effects on memory and attentional-executive network function in Alzheimer's disease. Proc Natl Acad Sci USA 2010;107:10256-10261.

-24 Buckner RL: Memory and executive function in aging and AD: multiple factors that cause decline and reserve factors that compensate. Neuron 2004;44:195-208.

25 Ideno Y, Takayama M, Hayashi K, Takagi H, Sugai Y: Evaluation of a Japanese version of the Mini-Mental State Examination in elderly persons. Geriatr Gerontol Int 2012;12:310-316. 